\title{
Nitrogen Fixation in Cultures of the Cyanobacterium Gloeocapsa (Gloeothece) sp. 1430/3 Incubated in the Dark
}

\author{
By PHilip M. MULlineAUX, JOHN R. GALlON AND \\ ALAN E. CHAPLIN* \\ Department of Biochemistry, University College of Swansea, Singleton Park, \\ Swansea SA2 8PP
}

(Received 22 September 1980; revised 31 October 1980)

Gloeocapsa sp. 1430/3 fixed $\mathrm{N}_{2}$ in the dark, but at a lower rate than in the light. Following the transfer of exponentially growing cultures to the dark, the rate of $\mathrm{N}_{2}$ fixation increased for between 2 and $5 \mathrm{~h}$ and then decreased, becoming negligible after $12 \mathrm{~h}$. No substantial increase in activity occurred for about $10 \mathrm{~h}$ following re-illumination. It is suggested that the decrease in nitrogenase activity which occurred about $5 \mathrm{~h}$ after transfer to the dark was not caused by exhaustion of carbon reserves but by a cessation of nitrogenase synthesis coupled with an irreversible inactivation of the enzyme, probably by $\mathrm{O}_{2}$. Subsequent recovery of activity apparently depended upon resynthesis of nitrogenase.

\section{INTRODUCTION}

After $4 \mathrm{~h}$ incubation in the dark, cultures of the unicellular cyanobacterium Gloeocapsa sp. LB795 fixed $\mathrm{N}_{2}$ at approximately $40 \%$ of the rate in the light (Gallon et al., 1973). In this respect, Gloeocapsa differs from the heterocystous cyanobacteria Anabaena cylindrica and Anabaenopsis circularis in which nitrogenase activity declined exponentially almost to zero during incubation for $4 \mathrm{~h}$ in the dark (Fay, 1976; Bottomley \& Stewart, 1977).

In both Chlorogloea fritschii (Fay, 1965) and Anabaenopsis circularis (Watanabe \& Yamamoto, 1967; Bottomley \& Stewart, 1977), $\mathrm{N}_{2}$ fixation in the dark could be maintained by the addition of a suitable exogenous carbon source, suggesting that in these species the limitation of carbon supply probably determines both the rate and duration of nitrogenase activity. During the first minute after transition from light to dark, the rate of $\mathrm{N}_{2}$ fixation by cultures of Gloeocapsa sp. $1430 / 3$ dropped to $40 \%$ of that in the light and this lower rate was maintained for up to 5 min (Mullineaux et al., 1980) and probably for much longer (Gallon et al., 1973). However, Mullineaux et al. (1980) concluded that limitations in neither the supply of ATP nor the availability of storage glucan could explain this lower rate of $\mathrm{N}_{2}$ fixation.

The object of the work reported here was to study the ability of Gloeocapsa sp. 1430/3 to fix $\mathrm{N}_{2}$ in the dark and also to investigate some of the factors which might influence this process.

\section{METHODS}

Growth of cultures. Gloeocapsa (Gloeothece) sp. CCAP 1430/3 (Culture Centre of Algae and Protozoa, Cambridge) was grown in 151 of sterile medium free of combined nitrogen (Gallon et al., 1978) and harvested during the period of exponential growth, 6 to $8 \mathrm{~d}$ after inoculation.

Acetylene reduction $\left(N_{2}\right.$ fixation). This was measured as described by Tözüm et al. (1977) except that cultures were assayed immediately after transfer to $150 \mathrm{ml}$ Erlenmeyer flasks and acetylene was added to a concentration of $10 \%(\mathrm{v} / \mathrm{v})$. Where indicated, the incubation medium contained chloramphenicol $\left(0.1 \mathrm{mg} \mathrm{ml}^{-1}\right)$ or $\mathrm{NH}_{4} \mathrm{Cl}$ (2 mM). 
Acetylene reduction under anaerobic conditions was measured after bubbling the cultures with $\mathrm{N}_{2}$ for 2 to 5 min prior to sealing the incubation vessels. That anaerobic conditions were maintained during the incubation period was demonstrated by including in these vessels a $1.5 \mathrm{ml}$ centrifuge tube containing $1 \mathrm{ml}$ of decolorized methylene blue $\left(50 \mathrm{mg} \mathrm{l}^{-1}\right)$ in $2 \mathrm{~mm}-\mathrm{NaOH}$.

Estimation of glucan and protein. Cultures were incubated in the light in an atmosphere containing ${ }^{14} \mathrm{CO}_{2}$ for $14 \mathrm{~h}$ as described by Mullineaux et al. (1980). The light source was then removed for $10 \mathrm{~h}$ after which the cultures were re-illuminated for a further $4 \mathrm{~h}$. Methanol extracts were prepared and examined for glucan or protein as described by Mullineaux et al. (1980). Protein synthesis was also measured in methanol extracts from a culture of Gloeocapsa $(50 \mathrm{ml})$ which had been concentrated 10 -fold and incubated with $1.85 \mathrm{MBq}\left[\mathrm{U}-{ }^{14} \mathrm{C} / \mathrm{protein}\right.$ hydrolysate $\left[1.85 \mathrm{GBq}(\mathrm{mmol} \mathrm{C})^{-1}\right]$ under the above conditions.

$\mathrm{O}_{2}$ consumption/evolution. This was measured polarographically at $25^{\circ} \mathrm{C}$ (Mullineaux et al., 1980).

Measurement of the cell density of cultures. This was performed as described by Tözüm \& Gallon (1979).

\section{RESULTS AND DISCUSSION}

Gloeocapsa sp. 1430/3 reduced acetylene after $4 \mathrm{~h}$ in the dark, though at a lower rate than in the light (Fig. 1). This confirms the results of Gallon et al. (1973) with the non-axenic strain, Gloeocapsa sp. LB795. In cultures harvested during the exponential phase of growth (6 to $8 \mathrm{~d}$ after inoculation), the rate of acetylene reduction steadily increased during incubation for up to $7 \mathrm{~h}$ in the light (Fig. 1). The rate in cultures transferred to darkness also increased over a period which varied between 2 and $5 \mathrm{~h}$, but it subsequently steadily decreased (Fig. 1). Occasionally, cultures were harvested during a phase in which acetylene reduction activity in the light was decreasing; the rate of acetylene reduction also decreased when such cultures were transferred to the dark. In all cases, the rate of acetylene reduction during the first 2 to $5 \mathrm{~h}$ of darkness was about $40 \%$ of the rate in the light. Addition of either chloramphenicol, which inhibits protein synthesis in prokaryotes, or $\mathrm{NH}_{4}^{+}$, an inhibitor of nitrogenase synthesis, prevented any increase in nitrogenase activity in both light and dark, suggesting that the increases were probably the result of a net synthesis of nitrogenase.

There were therefore three distinct phases in the response of $\mathrm{N}_{2}$ fixation in cultures of Gloeocapsa sp. 1430/3 to darkness. During the first minute the rate of $\mathrm{N}_{2}$ fixation fell sharply below the rate in an illuminated control culture (Mullineaux et al., 1980), probably as a result of limitation of ATP and/or reductant. For up to $5 \mathrm{~h}$ after the start of the dark period, the rate of $\mathrm{N}_{2}$ fixation by cultures harvested in the exponential phase of growth increased, although the rate was always lower than in the light. Subsequently the rate of $\mathrm{N}_{2}$ fixation decreased.

In the light ${ }^{14} \mathrm{CO}_{2}$ was incorporated into storage glucan (Fig. $2 a$ ), but following transfer to the dark there was a net loss of radioactivity from the previously labelled storage glucan. Upon re-illumination of the culture, the incorporation of ${ }^{14} \mathrm{CO}_{2}$ recommenced immediately, at a rate slightly greater than that during the previous light period. These data suggest that storage glucan is synthesized in the light and broken down in the dark in order to provide the energy requirements of the organism. However, this pattern of synthesis and breakdown did not correlate with the pattern of $\mathrm{N}_{2}$ fixation (Fig. $2 b$ ). Whilst the breakdown of storage glucan began immediately illumination was discontinued, nitrogenase activity did not start to decline until $4 \mathrm{~h}$ later. At the end of the dark period, the rate of acetylene reduction had fallen almost to zero even though the glucan pool was not completely exhausted. Furthermore, when cultures were re-illuminated, storage glucan synthesis started immediately but there was only a small increase in the rate of $\mathrm{N}_{2}$ fixation. Thus it appears that the decrease in the rate of $\mathrm{N}_{2}$ fixation which occurred after $5 \mathrm{~h}$ in the dark was not simply a result of a lack of storage glucan as a source of energy and reducing power.

$\mathrm{O}_{2}$ evolution ceased immediately the cultures were transferred to the dark, but it recommenced as soon as they were re-illuminated (Fig. $2 c$ ). Thus the inability of Gloeocapsa to fix $\mathrm{N}_{2}$ in the light after a period in the dark cannot be caused by the deprivation of ATP, and/or reducing power, derived directly from photosynthesis. After $12 \mathrm{~h}$ in the dark, there was no sustained nitrogenase activity for $10 \mathrm{~h}$ after re-illumination even though photosynthesis and glucan synthesis were proceeding normally. 


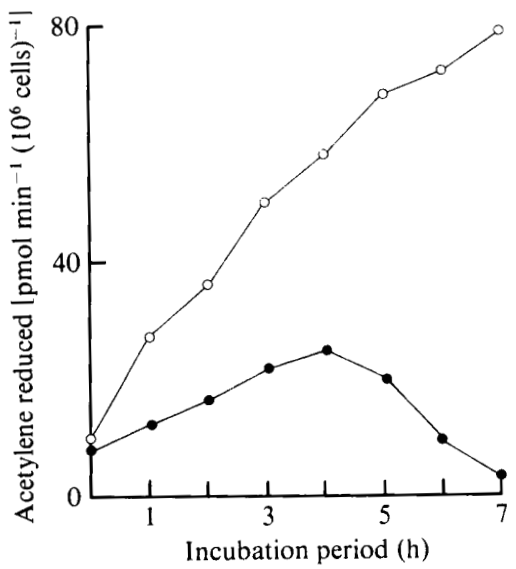

Fig. 1. Effect of transfer from light to dark (at zero time) on acetylene reduction by Gloeocapsa sp. $1430 / 3(O)$. The control culture $(O)$ was maintained in the light. The data shown here are from a single experiment but are typical. In a number of such experiments, the absolute rate of acetylene reduction varied considerably. However, the rate of acetylene reduction was always lower in the dark than in the light.
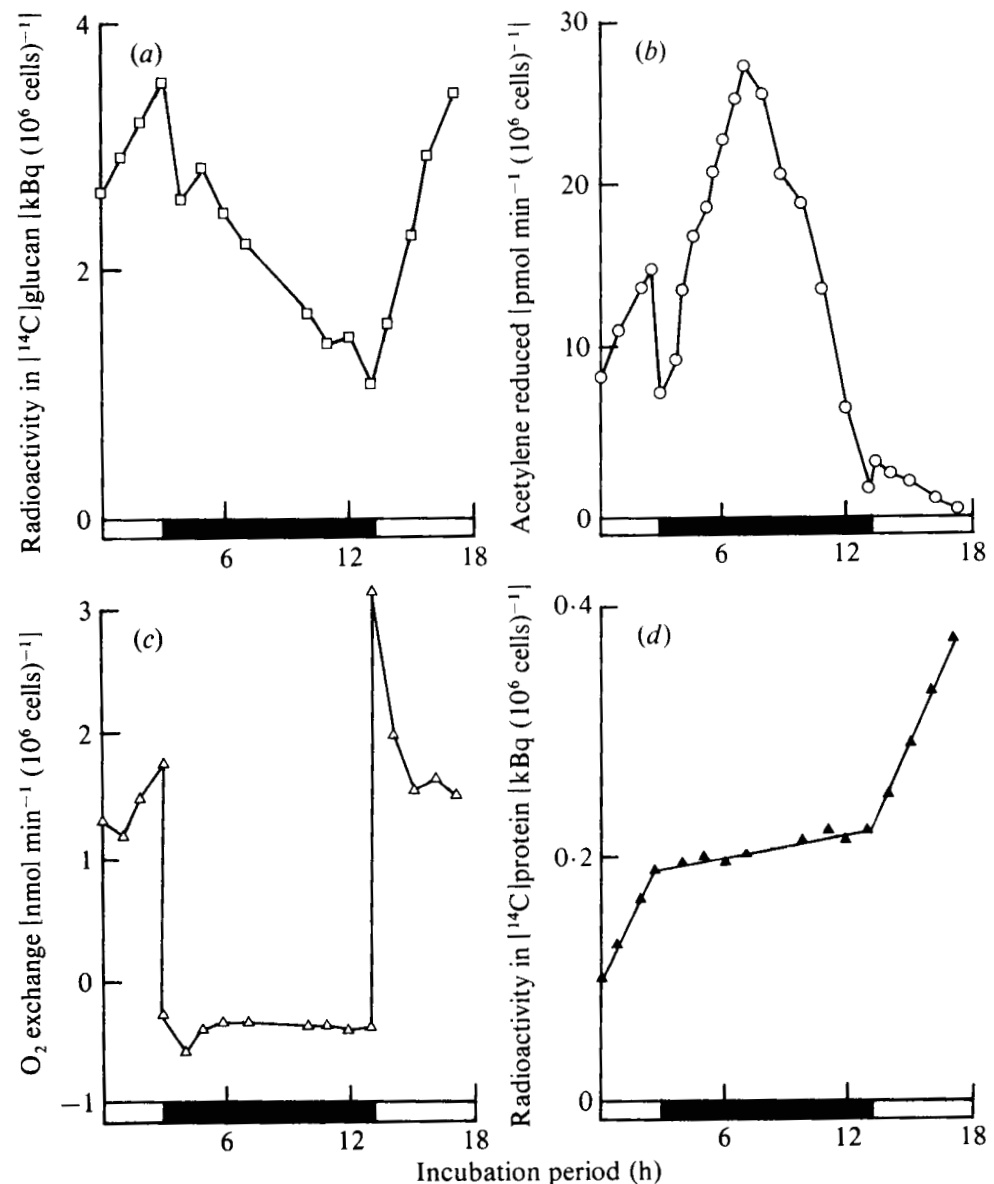

Fig. 2. Comparison of $(a){ }^{14} \mathrm{C}$ in storage glucan, $(b)$ acetylene reduction, $(c) \mathrm{O}_{2}$ exchange, and $(d){ }^{14} \mathrm{C}$ in protein in a culture of Gloeocapsa sp. 1430/3 subjected to a light-dark-light regime. The black areas indicate the periods of darkness. In (c), a positive value indicates $\mathrm{O}_{2}$ evolution and a negative value indicates $\mathrm{O}_{2}$ uptake. The data shown are from a single experiment but are typical. 
Measurements of the incorporation of ${ }^{14} \mathrm{CO}_{2}$ into protein during a light-dark-light regime (Fig. $2 d$ ) indicated that the rate of protein synthesis was lowered in the dark, to about $15 \%$ of that in the light. These results were confirmed by measurements of the incorporation of radioactivity from $\left[\mathrm{U}^{14}{ }^{14} \mathrm{C}\right.$ lprotein hydrolysate into protein. The rate of incorporation fell by $85 \%$ from $33 \mathrm{~Bq} \mathrm{~h}^{-1}\left(10^{6} \text { cells }\right)^{-1}$ in the light to $5.5 \mathrm{~Bq} \mathrm{~h}^{-1}\left(10^{6} \text { cells }\right)^{-1}$ in the dark. Protein synthesis increased to its pre-dark rate immediately after the cells were re-illuminated (Fig. $2 d$ ), but nitrogenase activity continued to decline (Fig. $2 b$ ). Therefore, the decrease in nitrogenase activity which occurred after a period in the dark was probably not the result of a general inhibition of protein synthesis.

In cyanobacteria, it seems unlikely that the activity of nitrogenase is modulated by intermediary metabolites (Stewart et al., 1975; Murry \& Benemann, 1979). $\mathrm{N}_{2}$ fixation would therefore continue at a rate determined largely by the supply of ATP and/or reductant or by the amount of nitrogenase in the cyanobacterial cell. Control of the latter might be determined by the relative rates of nitrogenase synthesis and inactivation, particularly by $\mathrm{O}_{2}$ (Bone, 1972).

In cultures transferred to the dark under anaerobic conditions, nitrogenase activity initially increased more rapidly than in cultures under dark aerobic conditions. However, after $5 \mathrm{~h}$, the rate under anaerobic conditions became constant whereas the rate under aerobic conditions began to decrease (results not shown). The initial increase in the rate of acetylene reduction in the dark under both aerobic and anaerobic conditions could be prevented by the addition of chloramphenicol or $\mathrm{NH}_{4}^{+}$and it therefore appeared to result from synthesis of nitrogenase. Synthesis apparently ceased after $5 \mathrm{~h}$ in the dark, leading, under aerobic conditions, to a net loss of nitrogenase activity as a consequence of inactivation of the enzyme by $\mathrm{O}_{2}$. However, under dark anaerobic conditions, $\mathrm{O}_{2}$ inactivation did not occur.

Nitrogenase activity recovered $10 \mathrm{~h}$ after re-illumination of a culture which had been incubated aerobically in the dark for $12 \mathrm{~h}$. The recovery was prevented by the addition of chloramphenicol or $\mathrm{NH}_{4}^{+}$either at the beginning or end of the dark period. The delay of $10 \mathrm{~h}$ in the recovery of nitrogenase activity in the light after a $12 \mathrm{~h}$ dark period may therefore result from delayed synthesis of new nitrogenase enzyme.

Treatment of Gloeocapsa with $1 \mathrm{~mm}$-EDTA for $20 \mathrm{~min}$ under aerobic conditions irreversibly inactivated any existing nitrogenase. Subsequent treatment of the culture with $5 \mathrm{mM}-\mathrm{CaCl}_{2}$ relieved the inhibition by EDTA and nitrogenase activity slowly recovered, probably as a result of de novo enzyme synthesis (Hamadi \& Gallon, 1979). When cultures of Gloeocapsa were incubated in the dark for various periods (between 0.5 and $6.5 \mathrm{~h}$ ) and nitrogenase was inactivated with EDTA as described above, the initial rate of synthesis of nitrogenase in both light and dark decreased with increasing length of dark pre-incubation (Fig. 3). In the dark, nitrogenase activity increased for between 1 and $3 \mathrm{~h}$ after addition of $\mathrm{CaCl}_{2}$ and then decreased, while in the light, activity increased for at least $5 \mathrm{~h}$.

These results could be explained by postulating either the accumulation in the dark of a compound which inhibits nitrogenase synthesis or activity, or the disappearance in the dark of a compound which is necessary for nitrogenase synthesis or activity. An effect on the activity of nitrogenase seems less likely, because there was no inhibition of nitrogenase activity in cultures incubated anaerobically in the dark. Since our results suggest that the initial increase in nitrogenase activity in the dark may be the result of nitrogenase synthesis, the cessation of the increase after 2 to $5 \mathrm{~h}$ in the dark may be caused by an interruption of this synthesis.

One inhibitor of nitrogenase synthesis that might accumulate in the dark is ammonia. Because $\mathrm{N}_{2}$ fixation initially continued in the dark but protein synthesis, and hence the utilization of ammonia, was markedly decreased, it is possible that ammonia might have accumulated to a level at which it would have repressed nitrogenase synthesis. However, this appears unlikely because $3 \mathrm{mM}$-L-methionine-DL-sulphoximine, which is known to reverse the repression of nitrogenase synthesis by ammonia in the light (Gallon et al., 1978), did not reverse the inhibition of nitrogenase synthesis which occurred after $5 \mathrm{~h}$ in the dark. An 


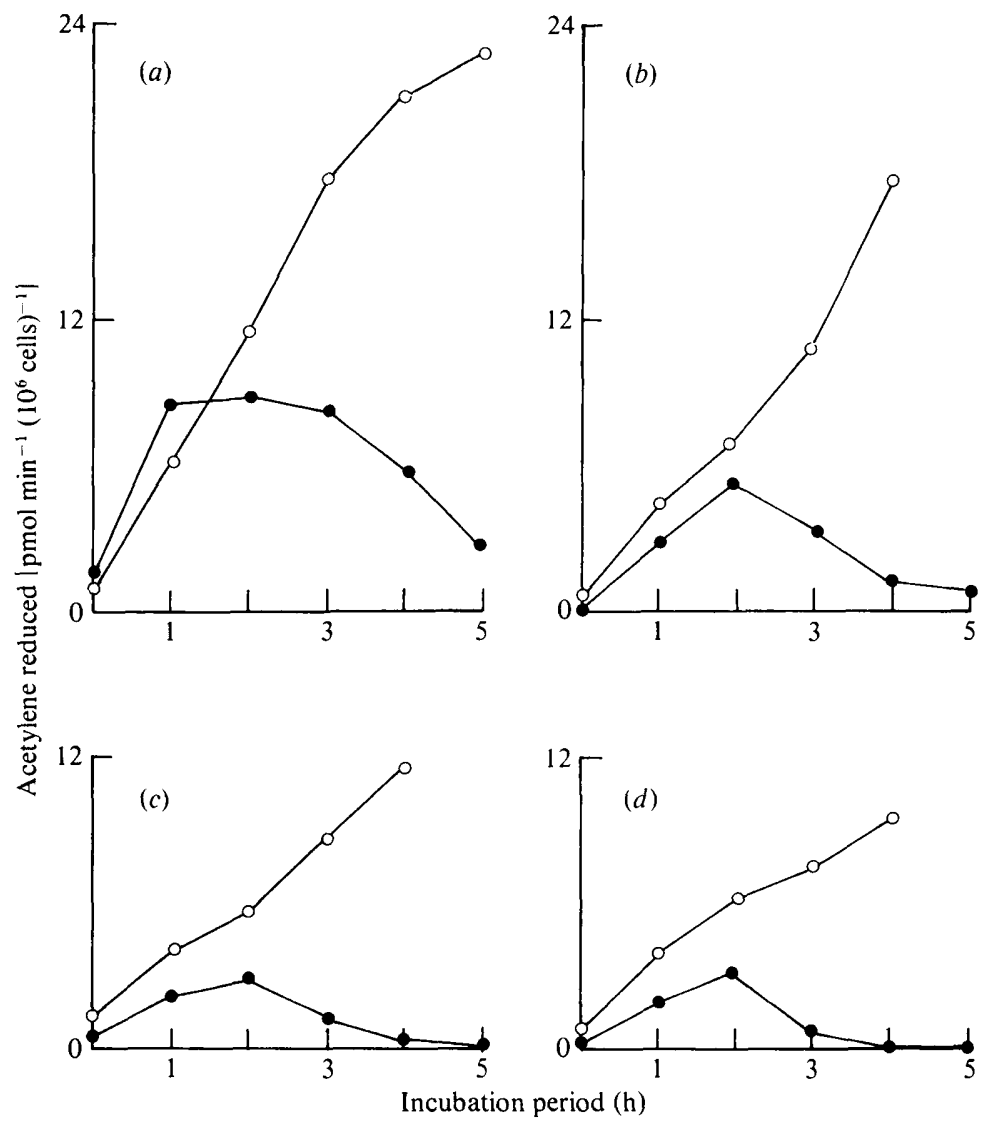

Fig. 3. Effect of dark incubation on nitrogenase synthesis by cultures of Gloeocapsa sp. 1430/3. Cultures harvested during the exponential phase of growth were incubated for $(a) 0.5 \mathrm{~h},(b) 2.5 \mathrm{~h},(c)$ $4.5 \mathrm{~h}$ and $(d) 6.5 \mathrm{~h}$ in the dark, and then treated with $1 \mathrm{mM}$-EDTA followed $20 \mathrm{~min}$ later by $5 \mathrm{mM}-\mathrm{CaCl}_{2}$. The cultures were then incubated in the dark (O) or in the light $(O)$ and the rate of acetylene reduction was measured hourly. The data shown are from a single experiment but are typical.

example of a compound necessary for nitrogenase synthesis which might disappear from cultures of Gloeocapsa incubated in the dark is mRNA, which has been shown to be unstable in the cyanobacterium Anabaena variabilis (Carr, 1973).

The above examples are purely speculative and there is, so far, no direct evidence that the disappearance of nitrogenase activity in the dark is caused by an effect on nitrogenase synthesis. However, in general terms, an inhibitor of nitrogenase synthesis might either be produced only in the dark or produced both in the light and in the dark but broken down more rapidly in the light. Either of these alternatives would allow the accumulation of the inhibitor in the dark. Subsequent transfer of cultures to the light would require the breakdown of this inhibitor before nitrogenase synthesis could begin. Since the intracellular level of inhibitor would depend upon the length of dark incubation, an inverse relationship between the rate of nitrogenase synthesis on transfer to the light and the length of pre-incubation in the dark might be expected. Similar arguments could be applied to the disappearance of a component essential for the synthesis of nitrogenase.

Whatever the mechanism, the response of acetylene reduction in Gloeocapsa to dark incubation appeared to differ markedly from that of heterocystous cyanobacteria such as Anabaena cylindrica and Anabaenopsis circularis. In these latter organisms, $\mathrm{N}_{2}$ fixation declined exponentially to zero within $4 \mathrm{~h}$ of transfer to darkness but resumed immediately 
upon re-illumination, although in Anabaenopsis circularis it could be maintained for long periods in the dark provided that an exogenous carbon source was supplied (Fay, 1965, 1976; Bottomley \& Stewart, 1977). This suggests that in these species, unlike Gloeocapsa, the rate of $\mathrm{N}_{2}$ fixation in the dark is limited mainly by the supply of energy and reducing power.

P.M.M. acknowledges with gratitude a Research Studentship from the Science Research Council.

\section{REFERENCES}

BonE, D. (1972). The influence of canavanine, $\mathrm{O}_{2}$ and urea on the steady-state levels of nitrogenase in Anabaena flos-aquae. Archiv für Mikrobiologie 86, 13-24.

Bottomley, P. J. \& Stewart, W. D. P. (1977). ATP and nitrogenase activity in nitrogen-fixing heterocystous blue-green algae. New Phytologist 79, 625-638.

CARr, N. G. (1973). Metabolic control and autotrophic physiology. In The Biology of Blue-Green Algae, pp. 39-65. Edited by N. G. Carr \& B. A. Whitton. Oxford: Blackwell Scientific Publications.

FAY, P. (1965). Heterotrophy and nitrogen fixation in Chlorogloea fritschii. Journal of General Microbiology 39, 11-20.

FAY, P. (1976). Factors influencing dark nitrogen fixation in a blue-green alga. Applied and Environmental Microbiology 31, 376-379.

Gallon, J. R., Kurz, W. G. W. \& LaRue, T. A. (1973). Isocitrate supported nitrogenase activity in Gloeocapsa sp. LB795. Canadian Journal of Microbiology 19, 461-465.

Gallon, J. R., Ul-Haque, M. I. \& Chaplin, A. E. (1978). Fluoroacetate metabolism in Gloeocapsa sp. LB795 and its relationship to acetylene reduction (nitrogen fixation). Journal of General Microbiology 106, 329-336.

Hamadi, A. F. \& Gallon, J. R. (1979). Studies on the role of calcium in acetylene reduction (nitrogen

fixation) by Gloeocapsa sp. 1430/3. Biochemical Society Transactions 7, 1266-1267.

Mullineaux, P. M., Chaplin, A. E. \& Gallon, J. R. (1980). Effects of a light to dark transition on carbon reserves, nitrogen fixation and ATP concentrations in cultures of Gloeocapsa (Gloeothece) sp. 1430/3. Journal of General Microbiology 120. 227-232.

Murry, M. A. \& BenemanN, J. R. (1979). Nitrogenase regulation in Anabaena cylindrica. Plant and Cell Physiology 20, 1391-1401.

Stewart, W. D. P., Haystead, A. \& Dharmawhadene. M. W. N. (1975). Nitrogen assimilation and metabolism in blue-green algae. In Nitrogen Fixation by Free-living Micro-organisms, pp. 129-158. Edited by W. D. P. Stewart. Cambridge: Cambridge University Press.

TözüM, S. R. D. \& Gallon, J. R. (1979). The effects of methyl viologen on Gloeocapsa sp. LB795 and their relationship to the inhibition of acetylene reduction (nitrogen fixation) by oxygen. Journal of General Microbiology 111, 313-326.

Tözüm, S. R. D.. Ul-Haque, M. I.. Chaplin, A. E. \& GaLlon, J. R. (1977). The effect of fluoroacetate on acetylene reduction by Gloeocapsa. Biochemical Society Transactions 5, 1482-1484.

Watanabe, A. \& Yamamoto, Y. (1967). Heterotrophic nitrogen fixation by the blue-green alga Anabaenopsis circularis. Nature, London 241, 738. 